Journal of Professional \& Applied Psychology

Original Article

\title{
Health-Related Behaviors and Social Media Usage in Young Adults: Mediating Role of Coping Strategies during COVID-19 Smart Lockdown
}

\author{
Faiza Khaliq ${ }^{1}$, Shahnila Tariq ${ }^{2}$, Saima Batool $^{3}$
}

\begin{abstract}
The study investigated the association between health-related behaviors, coping strategies and social media usage in young adults during COVID-19 smart lockdown as well as the mediating role of coping strategies between the relationships. It was hypothesized that coping strategies mediates the relationship between health-related behaviors and social media usage in young adults during COVID-19 smart lockdown. Through purposive sampling technique, data from (N=300) young adults with age range $18-35$ years $(M=23.67, S D=3.78)$ was collected from three private universities of Lahore. For data collection, lifestyle behavior change questionnaire by Chopra et al. (2021), coping scale by Hamby et al. (2013) and social networking usage questionnaire by Savita and Liyaqat (2018) were used. For the analysis, Pearson Product Moment Correlation, Mediation analysis, independent sample t-test and Analysis of variance were used. Coping strategies significantly mediated between health-related behaviors and social media usage in young adults during COVID-19 smart lockdown. Findings have practical implications for the expansion of different strategies for other population like adolescents, old age people, teachers, parents, and doctors, expecting to cope better with others during stressful or traumatic events.

Keywords: Health-related behaviors, Coping Strategies, Social Media Usage, Adults, COVID-19
\end{abstract}

Received: 11 Nov 2021; Revised Received:

27 Nov 2021; Accepted: 27 Nov 2021

${ }^{1}$ MPhil Scholar, Department of Applied Psychology, University of Management \& Technology, Lahore, Pakistan.

${ }^{2}$ Associate Professor, Department of Applied Psychology, University of Management \& Technology, Lahore, Pakistan.

${ }^{3}$ Psychiatrist, Department of Psychiatry and Behavioral Sciences, Fatima Memorial Hospital Lahore, Pakistan.

\section{Corresponding Author Email}

shahnila.tariq@umt.edu.pk

\section{Introduction}

Health-related behaviors are particular characteristics that can improve or harms physical, psychological, and social wellbeing now and in the future of individuals.
Individual's potential and their functioning are largely determined by the choices an individual makes about their lives are based on their health-related behaviors. Healthrelated behaviors are categorized into two main broad classes that are: healthsupporting behavior and health-damaging behavior (Havigerova et al., 2019; Slavich, 2020). Health-supporting behaviors are basically the positive activities that assist the person and lead towards the good health. These positives activities improve health, inhibit illness, identify disease or issue on time, detect any sort of disability at the earlier stages, and guard from jeopardy of injury (Samal et al., 2017). Health-damaging behaviors are those activities that are carried out by people which can increase the risk of illness, whether or not individual is having knowledge of the association between the

This article is distributed under the terms of the Creative Commons Attribution Non Commercial 4.0 License (http://www.creativecommons.org/licenses/by-nc/4.0/) which permits nonCommercial use, reproduction and distribution of the work without further permission provided the original work is attributed as specified. 
activities and illness. These activities do not contribute to good physical and mental health including inappropriate eating habits, lack of sleep, alcohol consumption, and poor hygiene, no physical exercise and safe sexual behaviors (Ntoumanis et al., 2020).

Coping strategies refers to the particular approaches which are used by individuals in diverse circumstances which change over the period of time, and are also liable on the elicited conditions (Cattelaens et al., 2019). Active coping incorporates systems like arranging, making a particular move, looking for help, positive reappraisal of the circumstance, or acknowledgment (Freire et al., 2020; Gustems-Carnicer et al., 2019). Avoidant coping strategies are those which include intellectual and social systems used to dodge the distressing circumstance, like interruption, refusal, and living in fantasy land (Tran et al., 2019).

Social media is based on different applications and websites that permits the users to create and post diverse life related contents and allow them to participate in networking world, where they can meet people virtually (Ramos et al., 2019). The most common applications of social media are Facebook, Whatsapp, Instagram, Snapchat, Twitter, and You Tube (Abbas et al., 2021). Social media as a set of virtual applications and tools that carry ways of interactions and communications for digital media operators by helping and providing knowledge on social media platforms. It has positive and negative outcomes which affect the individuals (Hassen \& Kibret, 2016).

The theoretical framework of the research was grounded on the theory of planned behavior by Ajzen (1991) which is based on these constructs: Attitude, behavioral intention, subjective norms, social norms, perceived power and perceived behavioral control. The coping circumplex model by Stanistawski (2019) model is based on eight coping styles and created a circumplex: positive emotional coping, efficiency, problem solving, and preoccupation with problem, negative emotional coping, helplessness, problem avoidance and hedonic disengagement. Social media engagement theory by Di Gangi and Wasko (2016) model centered on user experience, user engagement and their usage.

\section{Literature Review}

Social media was the first choice of people for getting information related to COVID-19 and health concerns (Gecer et al., 2020). Social media usage was more common in young adults, they used it for various reasons and the main reasons were to handle the situation better and explore things related to healthy lifestyle behaviors (Al Mamum \& Griffiths, 2019). Positive approach towards the traumatic condition was the main protective factor to keep themselves healthy (Babore et al., 2020). 80\% of the students took better precautions related to COVID-19 nervousness as they had knowledge and they strictly followed the precautions, focused on health-related behaviors and took precautionary measures (Baloran, 2020). Young adults reported that they used different social media sites to cope better during the stressful time of their lives by familiarizing themselves to new activities and they used diverse sites of social media as a tool for coping to deal with stressful event (Fernandes et al., 2020; Pahayahay \& Khalili-Mahani, 2020). Different social media applications like Facebook, Snapchat, Twitter, WhatsApp and YouTube etc. were the most important sources for sharing healthy behaviors, unique activities and information with others during COVID-19 or during COVID-19 smart lockdown (Hussain, 2020).

Adults who implemented altered coping strategies and kept themselves busy in various healthy activities including aerobics, walking, gardening and followed their daily life interests, enjoyed their stressful time and 
they enjoyed optimistic effects (Lades et al., 2020). Young adults used social media and technology for educational and creative purposes, and they were engaged in different activities by getting ideas from social media and coped best by using humorous memes with others (Cauberghe et al., 2021; Garfin, 2020). Further, young adults increased their use of social media as compared to preCOVID-19 pandemic. Moreover, findings of a research showed that there was no specific social media platform which was directly associated with the coping strategies, health knowledge and physical activity (Tarqi et al., 2020). Young adults focused on emotional and problem based coping strategies for dealing with stressful events in their lives (Baloch et al., 2021). People used religious and active coping to help the humankind and handled the stress level related to COVID-19 lockdown (Munawar \& Choudhry, 2021; Salman et al., 2020).

Social networking sites and their applications presented enormous benefits for both nonprofessionals and professionals during disturbing lockdown of COVID-19 (Haggag et al., 2021). Working people reported professional usage rates of $100 \%$ on the internet, $89 \%$ on apps, and $46 \%$ on social media. For professional use, they spent average 30 minutes per day on the internet, 10 minutes on apps, and 15 minutes on social media other sites. Furthermore, (94\%) used digital media for communication with colleagues and $23 \%$ for communication with others. It was increasingly noticeable that social networking sites and their applications presented enormous benefits for nonprofessionals university students (Abbas et al., 2021).

Social media usage and birth order have a significant relationship. Further, findings of a research concluded that internet addiction and birth order act with each other in locus to anxiety of students (Yang et al., 2021). Additionally, Marano (2017) observed
Adlerian theory (1964) and suggested that birth order and the number of siblings affect a child's potential. Also, findings concluded that an individual's own perception of his or her birth order is more important than the actual order. This psychological perception of birth order can be impacted by multiple factors (Jambon et al., 2019).

\section{Rationale of the Study}

It is very important how we take care of our health when daily routines have been disturbed. During many smart lockdown, people used different strategies to cope better with the stressful time of their life (Moore \& March, 2020). Due to the threat of COVID19 and its smart lockdown, social media communication goes beyond the delivery of messages and helps in developing the strong sense of disease prevention. Individual adapt different coping strategies, promote healthy behaviors and they moved to virtual world (Zhong et al., 2020). Therefore, the current research was designed to investigate the association between these important variables, health-related behaviors, coping strategies, and social media usage in young adults during COVID-19 smart lockdown.

\section{Objectives of the Study}

1. The main objective of the study was to examine the relationship between health-related behaviors, coping strategies and social media usage in young adults during COVID-19 smart lockdown.

2. Whether coping strategies mediates the relationship between healthrelated behaviors and social media usage in young adults during COVID19 smart lockdown.

\section{Hypotheses}

1. There was likely to be a significant relationship between health-related behaviors, coping strategies and social media usage in young adults during COVID-19 smart lockdown. 
2. Coping strategies mediates the relationship between health-related behaviors and social media usage in young adults during COVID19 smart lockdown.

3. There was likely to be a significant difference in status of participants and social

\section{Method}

\section{Sample and Sampling Technique}

A sample of $\mathrm{N}=300$ (aged 18-35 years) young adults through purposive sampling technique were taken from three different private universities of Lahore with equal distribution on the basis of gender. Regular university students who must use more than 3 social media sites (Facebook, Instagram, YouTube, Snapchat, WhatsApp etc.) on daily basis, must have 12 years or more level of education and be able to read and understand English were included in the study. Young adults who run online businesses, bloggers and social media influencers, have any physical disability and any psychological illness were excluded from the study.

\section{Measures \\ Consent Form and Demographic Information Sheet}

Written consent was taken from the participants, time for completing the questionnaire and confidentiality was clearly mentioned in the consent form. Demographic information sheet was formed to find out participant's age, gender, education, birth order, status of participants, leisure time activities and purpose of using social media.

\section{The Lifestyle Behavior Change Questionnaire}

It was developed by Chopra et al. in 2021. It is a 5-point Likert scale from (1) significantly increased, (2) slightly increased, (3) grossly similar, (4) slightly decreased and (5) significantly decreased. Scale has 20 items and overall scale alpha coefficient is .72 which shows good internal consistency. media usage in young adults during COVID19 smart lockdown.

4. There was likely to be a significant difference in the birth order of young adults and social media usage during COVID-19 smart lockdown.

\section{Coping Scale}

It was developed by Hamby et al. 2013. It is a 13 items scale which consists of 2 subscales appraisal (items 1,2,3,4,5,6 and 7) and behavioral (items 8,9,10,11,12, and 13). The coefficient alpha of appraisal subscale is .89 and the coefficient alpha of behavioral subscale is .75. Scale is based on 1-4 responses Likert scale, where 1 is (not true), 2 (little true), 3(somewhat true), and 4(mostly true) with .90 coefficient alpha which shows good internal consistency.

\section{Social Networking Usage Questionnaire}

It was created by Savita and Liyaqat in 2018. A 5-point Likert scale from 5 (Always), 4(often), 3(sometimes), 2 (rarely) to 1(never). The scale comprised of total 19 items constructed on 4 subscales which were academic (items 3,9,12,13,14,17,18), socialization (items 1,2,6,7,8), entertainment $(11,15,16,19)$ and informativeness (items $4,5,10)$. The scale had a .83 alpha coefficient which depicted good internal consistency.

\section{Procedure}

The reason for choosing this topic was to explore the impact of current circumstance of the COVID-19 smart lockdown. Scales were compiled into one questionnaire after the permission of authors. A demographic questionnaire comprised of personal data of the participant was used. A sample of $\mathrm{N}=300$ young adults was taken. The scales alongside the demographic data sheet were directed to every member of the sample. Written consent was taken from the members subsequent to clarifying the inspiration behind the study. Participants were briefed that the data will be kept confidential and might be utilized for research purposes. They were allowed to 
leave the study assuming they need it with no bias and punishment. 10-15 minutes were taken to finish the surveys. The gathered information was entered into the SPSS, v 21 for computable investigation.

\section{Results}

Table 1

Psychometric Properties of the Scales and Subscales $(N=300)$

\begin{tabular}{lcccc}
\hline \multicolumn{1}{c}{ Scales } & M & SD & Range & Cronbach's $\boldsymbol{\alpha}$ \\
\hline Health-related behaviors & 51.86 & 10.84 & $20-100$ & .80 \\
Coping strategies & 34.94 & 7.59 & $13-37$ & .83 \\
Appraisal & 18.89 & 4.49 & $7-28$ & .77 \\
Behavioural & 16.05 & 3.88 & $6-24$ & .69 \\
Social media usage & 51.71 & 13.80 & $19-69$ & .83 \\
Academic & 20.81 & 6 & $7-35$ & .77 \\
Socialization & 13.32 & 4.4 & $5-25$ & .73 \\
Entertainment & 10.05 & 3.59 & $4-20$ & .71 \\
Information & 7.57 & 2.95 & $3-15$ & .69 \\
\hline Note. MaMean; SD Standard & & & & \\
\hline
\end{tabular}

Note. $\mathrm{M}=$ Mean; $\mathrm{SD}=$ Standard Deviation.

Table 1 showed the descriptive statistics and reliability coefficient of measures used in study i.e. health-related behaviors, coping strategies and social media usage. All the measure showed overall good reliability coefficient.

Table 2

Correlation between Demographic Characteristics, Health-Related Behaviors, Coping Strategies, and Social Media Usage in Young Adults $(N=300)$

\begin{tabular}{lccccccccc}
\hline Variables & $\boldsymbol{n}$ & $\boldsymbol{M}$ & $\boldsymbol{S D}$ & $\mathbf{1}$ & $\mathbf{2}$ & $\mathbf{3}$ & $\mathbf{4}$ & $\mathbf{5}$ & $\mathbf{6}$ \\
\hline 1.Age & 300 & 23.66 & 3.77 & - & $.26^{* *}$ & $.80^{* *}$ & .03 & .03 & $.19^{* *}$ \\
2.Gender & 300 & 1.50 & .50 & - & - & $.19^{* *}$ & -.08 & -.10 & $.11^{*}$ \\
3.Edu & 300 & 1.47 & .77 & - & - & - & $.58^{* *}$ & .03 & $.20^{* *}$ \\
4.HRB & 300 & 51.26 & 10.64 & - & - & - & - & $.16^{* *}$ & $.20^{* *}$ \\
5.CS & 300 & 34.94 & 7.59 & - & - & - & - & - & $-.19^{* *}$ \\
6.SMU & 300 & 51.71 & 13.80 & - & - & - & - & - & - \\
\hline
\end{tabular}

Note. Edu $=$ Education; HRB $=$ Health-Related Behavior; $\mathrm{CS}=$ Coping Strategies; SMU = Social Media Usage; $* * p<0.01 .{ }^{*} p<0.05$ 
Table 2 indicated the results of correlation analysis that there was a significant positive relationship between demographic characteristics, health-related behaviors with social media usage and significant negative relationship between coping strategies and social media usage at 0.01 and 0.05 level of significance. The relationship showed that young adults who were concerned towards their health-related behaviors used more social media to maintain a healthy life style by exploring things. Further, results showed that rather than spending so much time on social media, young adults gave preference in adapting different coping strategies to deal with the situation of COVID-19 smart lockdown.

\section{Table 3}

Mediation Analysis between Health-Related Behaviors and Social Media Usage through Coping Strategies $(N=300)$

\begin{tabular}{|c|c|c|c|c|c|}
\hline \multirow[b]{3}{*}{ Antecedent } & \multicolumn{5}{|c|}{ Consequent } \\
\hline & \multicolumn{2}{|c|}{$\mathrm{CS}(\mathrm{M})$} & & \multicolumn{2}{|c|}{ SMU (Y) } \\
\hline & $\beta$ & $S E$ & & $\beta$ & $S E$ \\
\hline \multirow[t]{2}{*}{ Constant } & $29.05 * * *$ & 3.85 & & $50.91 * * *$ & 4.77 \\
\hline & $.11 * * *$ & .04 & $c^{\prime}$ & $.31 * * *$ & .07 \\
\hline $\operatorname{HRB}(\mathrm{X})$ & & & & & \\
\hline \multirow[t]{2}{*}{$\mathrm{CS} \quad(\mathrm{M})$} & - & - & $b$ & $-.43 * * *$ & .10 \\
\hline & $F(1,298)=$ & $\begin{array}{l} \\
<.000 \\
\end{array}$ & & $F(2,297)=1$ & $p<.000$ \\
\hline
\end{tabular}

Note: $\beta=$ standardized regression coefficient

The results of Table 3 indicated that the indirect effect of health-related behaviors on social media usage through coping strategies was significant, $\beta=.01,95 \%$ CI $[-.09,-.01]$.
Therefore, coping strategies significantly mediated between health-related behaviors and social media usage in young adults (see Figure 1).

\section{Figure 1}

Coping Strategies as a Mediator

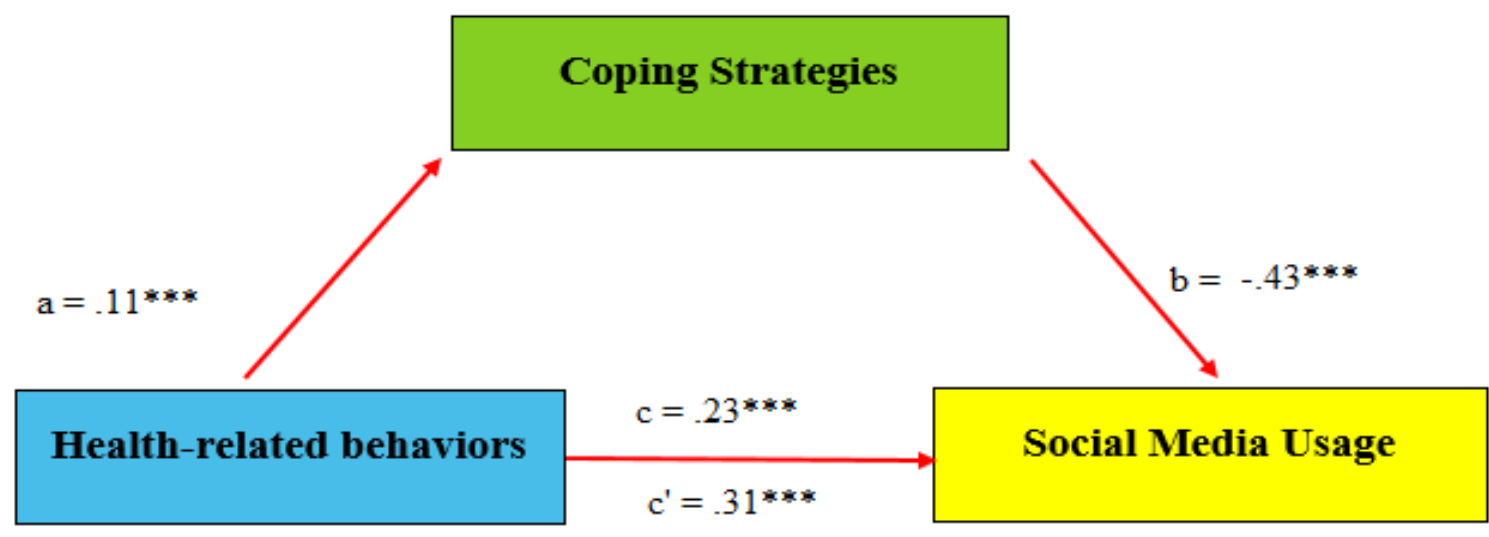




\section{Table 4}

Behavioral Coping Strategies used by Young Adults during COVID-19 Smart Lockdown $(N=300)$

\begin{tabular}{lcc}
\hline Activities & f & \% \\
\hline Reading & 90 & 30 \\
Physical activities & 84 & 28 \\
Online activities & 70 & 23.3 \\
Others & 30 & 10 \\
None & 15 & 5 \\
Art and craft & 11 & 3.7 \\
\hline
\end{tabular}

Note. $\mathrm{f}=$ Frequency; $\%=$ Percentage

Table 4 indicated the results of descriptive statistics and it revealed the frequencies and percentages of behavioral coping strategies used by young adults during COVID-19 smart lockdown. Findings showed that young adults adapted different behavioral coping strategies during COVID-19 smart lockdown (See Figure 2).

\section{Figure 2}

Behavioral Coping Strategies by Young Adults

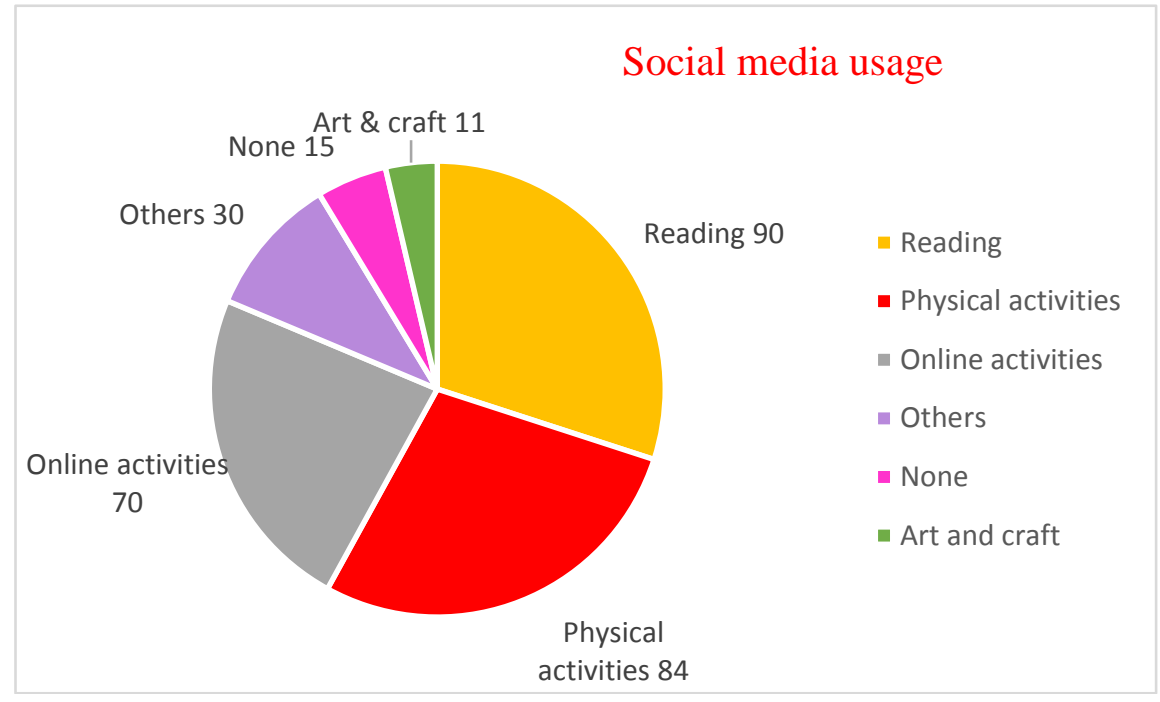




\section{Table 5}

Independent Sample t-test Comparing Status of Young Adults in terms of Social Media Usage $(N=300)$

\begin{tabular}{lccc}
\hline Variable & $\begin{array}{c}\text { Professionals } \\
(\mathrm{n}=109)\end{array}$ & $\begin{array}{c}\text { Non-professionals } \\
(\mathrm{n}=191)\end{array}$ & $95 \% \mathrm{CI}$
\end{tabular}

\begin{tabular}{|c|c|c|c|c|c|c|c|c|c|}
\hline & $M$ & $S D$ & $M$ & $S D$ & $t(62.1)$ & $p$ & $L L$ & $U L$ & Cohen's d \\
\hline SMU & 58.02 & 13.66 & 51.36 & 13.13 & 3.1 & .56 & -12.27 & -2.80 & 0.49 \\
\hline
\end{tabular}

Note. $\mathrm{CI}=$ Confidence Interval; $\mathrm{LL}=$ Lower Limit; UL = Upper Limit; SMU =Social Media Usage

Table 5 indicated the results of independent sample t-test and revealed non-significant status differences in terms of social media usage. No significant differences were found between professionals and non-professionals young adults in terms of social media usage during COVID-19 smart lockdown.

\section{Table 6}

One Way ANOVA Comparing Birth Order of Young Adults with Social Media Usage $(N=300)$

\begin{tabular}{|c|c|c|c|c|c|c|c|c|c|c|c|}
\hline \multirow[t]{2}{*}{ Variable } & \multicolumn{2}{|c|}{$\underset{(n=14)}{O C}$} & \multicolumn{2}{|c|}{$\begin{array}{c}\text { FB } \\
(n=68)\end{array}$} & \multicolumn{2}{|c|}{$\begin{array}{c}\text { MB } \\
(n=152)\end{array}$} & \multicolumn{2}{|c|}{$\begin{array}{c}\text { LB } \\
(n=66)\end{array}$} & $\begin{array}{l}F \\
(3,296)\end{array}$ & \multirow{2}{*}{$p$} & $\begin{array}{c}\text { Partial } \\
\eta^{2}\end{array}$ \\
\hline & $M$ & $S D$ & $M$ & $S D$ & $M$ & $S D$ & $M$ & $S D$ & & & \\
\hline SMU & 49.35 & 16.56 & 57.60 & 15.25 & 50.03 & 12.63 & 50.00 & 12.82 & 5.58 & .001 & .05 \\
\hline
\end{tabular}

Note. $\mathrm{M}=$ Mean; $\mathrm{SD}=$ Standard Deviation; $\mathrm{OC}=$ Only Child; $\mathrm{FB}=$ First Born; $\mathrm{MB}=$ Middle Born; $\mathrm{LB}=$ Last Born

Table 6 showed results of One way ANOVA and it indicated that birth order of young adults during COVID-19 smart lockdown varies among four groups $F(3,296)=5.58$, $p<.05, \eta^{2}=0.52$. Similarly, variability in the scores of birth order was accounted with the medium effect size. 
Table 6.1

Post Hoc Test of Young Adults in Terms of Birth Order and Social Media Usage $(N=300)$

\begin{tabular}{clllccc}
\hline $\boldsymbol{I}$ & \multicolumn{1}{c}{$\boldsymbol{J}$} & $\boldsymbol{M D}$ & $\boldsymbol{S E}$ & $\boldsymbol{p}$ & $\boldsymbol{L B}$ & $\boldsymbol{U B}$ \\
\hline Only child & First born & -8.24 & 3.96 & .208 & -18.73 & 2.24 \\
& Middle born & -.68 & 3.77 & 1.00 & -10.66 & \\
& Last born & -.64 & 3.97 & 1.00 & & 9.30 \\
& & & & & -11.16 & \\
\multirow{3}{*}{ First born } & & & & & & 9.87 \\
& Middle born & 7.56 & 1.96 & .001 & 2.34 & 12.77 \\
& Last born & 7.60 & 2.33 & 0.07 & 1.42 & \\
& & & & & & 13.78
\end{tabular}

$\begin{array}{lllllll}\text { Middle born } & \text { Last born } & .03 & 1.99 & 1.00 & -5.23 & 5.30\end{array}$

Note. $\mathrm{MD}=$ Mean Difference; $\mathrm{SE}=$ Standard Error; $\mathrm{CI}=$ Confidence Interval; $\mathrm{LB}=$ Lower Bound; $\mathrm{UB}=$ Upper Bound

Table 6.1 indicated the results of multiple comparisons post hoc test Hochberg's GT2. The results of the multiple comparisons showed that first born and middle born had significant differences. No significant

\section{Discussion}

The main objectives of the study were to examine the relationship between healthrelated behaviors, coping strategies and social media usage and whether coping strategies mediates the relationship between health-related behaviors and social media usage in young adults during COVID-19 smart lockdown. Findings of the recent exploration supported the hypotheses.

First hypothesis was that there was likely to be a significant relationship between healthrelated behaviors, coping strategies and social media usage in young adults during COVID-19 smart lockdown. Results of correlation analysis showed that there was a significant positive relationship between demographics characteristics, health-related behaviors with social media usage and significant negative relationship between coping strategies and social media usage. Young adults who were concerned towards their health-related behaviors used more social media to maintain a healthy life style by exploring things (Goodyear et al., 2019). differences were indicated in other groups. Conclusively, first born and middle born showed more differences as compared to the other groups.

Further, results showed that rather than spending so much time on social media, young adults gave preference in adapting different behavioral coping strategies to deal with the stressful time of COVID-19 smart lockdown (Mathias et al., 2020). People used social media for getting information related to COVID-19 and health-related issues (Gecer et al., 2020). With regards to demographics, age, gender, education showed significant relationship with social media usage. Young adults were the ones who started using more social media and accepted most of the sites during COVID-19 smart lockdown (Mahmood et al., 2020). They shared healthy diet or exercise plans with others, taking healthy diet and controlled themselves from taking unhealthy food. Smokers quit smoking as well, as it was injurious to health and corona virus and smoking both left bad effect on lungs (Tarqi et al., 2020). Result of the first hypothesis is supported by prior researches.

Second hypothesis was that coping strategies mediates the relationship between health- 
related behaviors and social media usage in young adults during COVID-19 smart lockdown. Result of the second hypothesis showed that coping strategies significantly mediated between health-related behaviors and social media usage in young adults. They improved their dietary patterns in a healthy manner and focused on their health-related behaviors by frequent use of social media during COVID-19 smart lockdown (Chopra et al., 2021). They used different social media sites as a tool for coping to deal in a better way with stressful events. There came a time when they became bored as well from using social media. It was the time when many of them engaged themselves into different activities, such as, reading, physical activities, cooking, gardening, and painting (Pahayahay \& Khalili-Mahani, 2020). Young adults who used social media to cope with feelings of isolation and nervousness during COVID-19 smart lockdown adapt diverse coping strategies for passing their time (Cauberghe et al., 2021). Results of the previous researches supported the result of current study.

Third hypothesis of the study was that there was likely to be a significant difference in status of participants and social media usage during COVID-19 smart lockdown. The research presented new empirical findings regarding social media usage by professionals and non-professionals young adults during COVID-19 smart lockdown. No significant differences between professionals and non-professionals were revealed from the findings of the current research. During COVID-19 smart lockdown, things switched to virtual world. Workplaces adopted long-term work-fromhome policies for their employees (Feng \& Savani, 2020). Professionals begun home working (Veluchamy et al., 2021). Likewise, non-professionals additionally needed to remain at home, they utilized it for various purposes (Vyas \& Butakhieo, 2021).Results of the previous research were constant with the results of current research.

Fourth hypothesis of the study was that there was likely to be a significant difference in birth order status of participants and social media usage during COVID-19 smart lockdown. Result of the fourth hypothesis revealed that first born and middle born had significant differences. No significant differences were indicated in other group i.e. only child and last born. Result of the fourth hypothesis is supported by the earlier researches conducting on birth order. First born wanted to be with others to stay healthy and feel better, so they used more social media. Further, first-born used a wider variety of different sources of information (e.g., websites, mass media, social media). On the other hand, it was observed that middle born used first born and their parents as a model with whom to identify. By observing their older siblings, middle born tend to develop greater reliance. Just like first born, they spent time on social media in maintaining relationships with others during COVID-19 smart lockdown (Fukuya et al., 2021).

\section{Conclusion}

COVID-19 which was declared as the global health crisis helped increase the use of social media during smart lockdown. There were no such easy ways to kept busy, socially and emotionally healthy from distress when pandemic was attacking the humans. In short, from the past year, people's life style was totally changed, especially changes related to their health behaviors, physical exercise, disturbance in sleep, inadequate diet or eating habits and alcohol intake. These healthrelated behaviours can be seen in optimistic and adverse manners (Legnani et al., 2020). For dealing with the stressful time of the life during COVID-19 smart lockdown, people adapt different coping strategies, their thoughts and behaviors helped them a lot to deal with it (Stephenson \& De Longis, 2020). 
Social media is recognized as a source of strengthening relations. During the COVID19 smart lockdown, that time social media became a necessity, people spent time with others through social media and cope best during their stressful time. Foremost benefit of social media was that it spreads consciousness and give social facility to the people who were quarantined and faced difficulties in meeting with people during smart lockdown (Singh et al., 2020).

\section{Suggestions}

For further studies here are the following suggestions. Sample size can be stretched out to make the substantial generalizability. For more thorough outcomes, we can take general population for additional investigations.

\section{Implications}

The current review provided knowledge in interfacing with others, wellbeing-related practices, and adapting coping techniques

\section{References}

Abbas, J., Wang, D., Su, Z., \& Ziapour, A. (2021). The Role of Social Media in the Advent of COVID-19 Pandemic: Crisis Management, Mental Health Challenges and Implications. Risk Management and Healthcare Policy, 14(5), 1917-1932. https:// doi: 10.2147/RMHP.S284313.

Adler A. (1964). In: Problems of Neurosis: A Book of Case Histories. Mairet P, editor. New York, NY: Harper \& Row, Publishers, Incorporated.

Ajzen, I. (1991). The theory of planned behavior: Frequently asked questions. Human Behavior and Emerging Technologies, 2(4), 314324. https://doi.org/10.1002/hbe2.195.

Al Mamun, M. A., \& Griffiths, M. D. (2019). The association between Facebook addiction and depression: A pilot through social media of some sort, which was significant during COVID- 19 smart lockdown. One unique effect is taking part in practices around good dieting and practice and distinctive positive exercises to keep us occupied while utilizing diverse web-based media destinations. Findings had coherent consequences for the advancement of assorted techniques for different populations like teenagers, instructors, guardians, specialists, and so on expecting to more readily deal with their ways of life during unpleasant or awful mishaps.

\section{Conflict of Interest}

There is no conflict of interest declared by authors.

\section{Source of Funding}

The authors declared no source of funding.

survey study among Bangladeshi students. Psychiatry Research, 27(1), 628-633.

https://doi.org/10.1016/j.psychres.20 18.12 .039

Babore, A., Lombardi, L., Viceconti, M. L., Pignataro, S., Marino, V., Crudele, M., \& Trumello, C. (2020). Psychological effects of the COVID2019 pandemic: Perceived stress and coping strategies among healthcare professionals. Psychiatry

research, 293(11), 113366113378.http:// doi: 10.1016/j.psychres.2020.113366.

Baloch, G. M., Kamaludin, K., Chinna, K., Sundarasen, S., Nurunnabi, M., Khoshaim, H. B., \& Baloch, L. G. (2021). Coping with COVID-19: The Strategies Adapted by Pakistani Students to Overcome Implications. International Journal of Environmental Research and 
Public Health, 18(4), 1-10. https://doi.org/10.3390/ijerph180417 99.

Baloran, E. T. (2020). Knowledge, attitudes, anxiety, and coping strategies of students during COVID-19 pandemic. Journal of loss and trauma, 25(8), 635-642. https://doi.org/10.1080/15325024.20 20.1769300 .

Cattelaens, K., Schewe, S., \& Schuch, F. (2019). Treat to target-participation of the patient. Zeitschrift fur Rheumatologie, 78(5), $\quad$ 416421.http:// doi: 10.1007/s00393-0190629-4.

Cauberghe, V., Van Wesenbeeck, I., De Jans, S., Hudders, L., \& Ponnet, K. (2021). How adolescents use social media to cope with feelings of loneliness and anxiety during COVID-19 lockdown. Cyberpsychology,

Behavior, and Social Networking, 24(4), 250-257. https://doi.org/10.1089/cyber.2020.0 478.

Chopra, S., Ranjan, P., Malhotra, A., Sahu, A., Dwivedi, S. N., Baitha, U., \& Kumar, A. (2021). Development and validation of a questionnaire to evaluate the impact of COVID-19 on lifestyle-related behaviours: eating habits, activity and sleep behaviour. Public health nutrition, 24(6), 1275-1290. http://doi:10.1017/S1368980020004 656.

Di Gangi, P. M., \& Wasko, M. M. (2016). Social media engagement theory: Exploring the influence of user engagement on social media usage. Journal of Organizational and End User Computing (JOEUC), 28(2), $53-$ 73.http://doi:10.4018/JOEUC.20160 40104.
Feng, Z. and Savani, K. (2020), "Covid-19 created a gender gap in perceived work productivity and job satisfaction: implications for dualcareer parents working from home", Gender in Management, 35(8), 719-736. https://doi.org/10.1108/GM-072020-0202.

Fernandes, B., Biswas, U. N., Mansukhani, R. T., Casarín, A. V., \& Essau, C. A. (2020). The impact of COVID-19 lockdown on internet use and escapism in adolescents. Revista de psicología clínica con niños y adolescentes, 7(3), 59-65.http:// doi:10.21134/rpcna.2020.mon.2056

Freire, C., Ferradás, M. D. M., Regueiro, B., Rodríguez, S., Valle, A., \& Núñez, J. C. (2020). Coping strategies and selfefficacy in University students: a person-centered approach. Frontiers in psychology, 11(5), 841-852. https://doi.org/10.3389/fpsyg.2020.0 0841.

Fukuya, Y., Fujiwara, T., Isumi, A., Doi, S., \& Ochi, M. (2021). Association of Birth Order with Mental Health Problems, Self-Esteem, Resilience, and Happiness Among Children: Results From A-CHILD Study. Frontiers in Psychiatry, 12(4), $1-15$. https://doi.org/10.3389/fpsyt.2021.63 8088

Garfin, D. R. (2020). Technology as a coping tool during the coronavirus disease 2019 (COVID- 19) pandemic: Implications and recommendations. Stress and Health, 36(4), 555-559.http:// doi: 10.1002/smi.2975.

Geçer, E., Yıldırım, M., \& Akgül, Ö. (2020). Sources of information in times of health crisis: evidence from Turkey during COVID-19. Journal of Public 
Health, 29(10), 1-7.http:// doi: 10.1007/s10389-020-01393-x

Goodyear, V. A., Armour, K. M., \& Wood, H. (2019). Young people and their engagement with health-related social media: New perspectives. Sport, education and society, 24(7), 673-688. https://doi.org/10.1080/13573322.20 17.1423464 .

Gustems-Carnicer, J., Calderón, C., \& Calderón-Garrido, D. (2019). Stress, coping strategies and academic achievement in teacher education students. European Journal of Teacher Education, 42(3), 375-390. https://doi.org/10.1080/02619768.20 19.1576629 .

Haggag, O., Haggag, S., Grundy, J., \& Abdelrazek, M. (2021, May). COVID-19 vs Social Media Apps: Does Privacy Really Matter? In 2021 IEEE/ACM 43rd International Conference on Software Engineering: Software Engineering in Society (ICSE-SEIS) (pp. 48-57). IEEE.http://doi: 10.1109/ICSESEIS52602.2021.00014

Hassen, A., \& Kibret, T. B. (2016). HealthRelated Behaviors. Health Consciousness and Psychological Wellbeing among Teaching Faculty in Jimma University, Ethiopia. Clin Exp Psychol, 2(1), 1-8. http://doi: 10.4172/2471-2701.1000113

Hamby, S., Grych, J., \& Banyard, V. (2013). Resilience portfolios and polystrengths: Identifying protective factors associated with thriving after adversity. Psychology of violence, $8(2), \quad$ 171-172.http:// doi:10.1002/jcop.22220.

Havigerová, J. M., Dosedlová, J., \& Burešová, I. (2019). One health behavior or many health-related behaviors? Psychology research and behavior management, 12(10), 18.http://doi: 10.2147/PRBM.S17369 2.

Hussain, W. (2020). Role of social media in covid-19 pandemic. The International Journal of Frontier Sciences, 4(2), 59-60. https://doi.org/10.37978/tijfs.v4i2.14 4.

Jambon, M., Madigan, S., Plamondon, A., Daniel, E., \& Jenkins, J. M. (2019). The development of empathic concern in siblings: A reciprocal influence model. Child development, 90(5), 1598-1613. https://doi.org/10.1111/cdev.13015

Lades, L. K., Laffan, K., Daly, M., \& Delaney, L. (2020). Daily emotional well- being during the COVID- 19 pandemic. British journal of health psychology, 25(4), 902-911. http://doi: 10.1111/bjhp.12450

Legnani, R. F. D. S., Legnani, E., Andrade, T. A., Martins, R. V., Gustave, E. L. D., \& Campos, W. D. (2020). WebCas electronic questionnaire to evaluate health-related behaviors of schoolchildren. Motriz: Revista de Educação Física, 26(3), 15. https://doi.org/10.1590/S19806574202000030041.

Mahmood, Q. K., Jafree, S. R., \& Qureshi, W. A. (2020). The psychometric validation of FCV19S in Urdu and socio-demographic association with fear in the people of the Khyber Pakhtunkhwa (KPK) province in Pakistan. International Journal of Mental Health and Addiction, 19(6), 1-11. https://doi.org/10.1007/s11469020-00371-4.

Marano, K. (2017). An Analysis of Empirical Validity of Alfred Adler's Theory of Birth Order. Alétheia: Revista Académica de la Escuela de Postgrado de la Universidad 
Femenina del Sagrado CorazónUnifé, 2(1), 1-14.http://doi: 10.21081/AX0082.

Mathias, K., Rawat, M., Philip, S., \& Grills, N. (2020). We've got through hard times before: acute mental distress and coping among disadvantaged groups during COVID-19 lockdown in North India-a qualitative study. International journal for equity in health, 19(1), 1-12.http:// doi: 10.1186/s12939-020-01345-7.

Moore, K. A., \& March, E. (2020). Socially Connected during COVID-19: Online social connections mediate the relationship between loneliness and positive coping strategies. Research square, 1(6), 1-14. https://doi.org/10.21203/rs.3.rs35835/v1.

Munawar, K., \& Choudhry, F. R. (2021). Exploring stress coping strategies of frontline emergency health workers dealing Covid-19 in Pakistan: A qualitative inquiry. American journal of infection control, 49(3), 286-292. http://doi:

10.1016/j.ajic.2020.06.214.

Ntoumanis, N., Ng, J. Y., Prestwich, A., Quested, E., Hancox, J. E., ThøgersenNtoumani, C., \& Williams, G. C. (2020). A meta-analysis of selfdetermination theory-informed intervention studies in the health domain: effects on motivation, health behavior, physical, and psychological health. Health Psychology Review, 15(2), 1-31. http://doi: 10.1080/17437199.2020.1718529.

Pahayahay, A., \& Khalili-Mahani, N. (2020). What Media Helps, What Media Hurts: A Mixed Methods Survey Study of Coping with COVID-19 Using the Media Repertoire Framework and the Appraisal Theory of Stress. Journal of medical Internet research, 22(8), 1-20.http:// doi: 10.2196/20186.

Ramos, R. F., Rita, P., \& Moro, S. (2019). From institutional websites to social media and mobile applications: A usability perspective. European Research on Management and Business Economics, 25(3), 138-143. https://doi.org/10.1016/j.iedeen.2019 .07 .001 .

Salman, M., Asif, N., Mustafa, Z. U., Khan, T. M., Shehzadi, N., Hussain, K., \& Khan, M. T. (2020). Psychological impact of COVID-19 on Pakistani university students and how they are coping. Medrxiv, 2(5), 1-17. https://doi.org/10.3390/ijerph171866 03.

Samal, S., Mohanti, D., Born, E., \& Bircher, J. (2017). Teaching of health with the Meikirch model to indigenous people improves their health-supporting behavior: A pilot study. Medical Journal of Dr. DY Patil University, 10(1), 17-20.http:// DOI: 10.4103/0975-2870.197902.

Savita, G., \& Liyaqat, B. (2018). Social networking usage questionnaire: development and validation in an Indian higher education context. Turkish Online Journal of Distance Education, 19(4), 214-227. https://doi.org/10.17718/tojde.47191 8.

Singh, S., Dixit, A., \& Joshi, G. (2020). "Is compulsive social media use amid COVID-19 pandemic addictive behavior or coping mechanism? Asian journal of psychiatry, 54(12), 1-22.http:// doi: 10.1016/j.ajp.2020.102290

Slavich, G. M. (2020). Social safety theory: a biologically based evolutionary perspective on life stress, health, and behavior. Annual review of clinical psychology, 16(5), 265- 
295.http:// doi: 10.1146/annurevclinpsy-032816-045159.

Stanisławski, K. (2019). The coping circumplex model: an integrative model of the structure of coping with stress. Frontiers 694-717. psychology, 10(4), in https://doi.org/10.3389/fpsyg.2019.0 0694.

Stephenson, E., \& DeLongis, A. (2020). Coping Strategies. The Wiley Encyclopedia of Health Psychology, 2(9), 55-60. https://doi.org/10.1002/97811190578 40.ch50.

Tarqi, A., Khan, S. R., \& Basharat, A. (2020). Internet use, ehealth literacy, and dietary supplement use among young adults in Pakistan: cross-sectional study. Journal of Medical Internet Research, 22(6), 1-9.http:// doi: 10.2196/17014.

Tran, A. W., \& Lumley, M. N. (2019). Internalized stigma and student wellbeing: The role of adaptive and maladaptive coping. Social Work in Mental Health, 17(4), 408-425. https://doi.org/10.1080/15332985.20 18.1563023.

Veluchamy, D. R., Kumar, A., \& Dey, B. (2021). Feasibility Study on Implementing HR Practices for Migrant Workers during Pandemics: Future-Proofing Human Resource Management. Journal of Critical Reviews, 8(3), 137-148.http:// doi:10.31838/jcr.08.03.15.

Vyas, L., \& Butakhieo, N. (2021). The impact of working from home during COVID-19 on work and life domains: an exploratory study on Hong Kong. Policy Design and Practice, 4(1), 59-76. https://doi.org/10.1080/25741292.20 20.1863560 .
Yang, H. M., Li, Y., Zhang, M. X., Tao, V. Y., Tong, K. K., \& Wu, A. M. (2021). Locus of control, coping flexibility, and post-migration growth among mainland Chinese university students in Macao. International Journal of Intercultural Relations, 85(11), 1325.

https://doi.org/10.1016/j.ijintrel.2021 .08 .012 .

Zhong, B., Huang, Y., \& Liu, Q. (2020). Mental health toll from the coronavirus: Social media usage reveals Wuhan residents' depression and secondary trauma in the COVID19 outbreak. Computers in human behavior, 114(1), 124.http;//doi: 10.1016/j.chb.2020.106 524. 